\title{
PERANCANGAN OTOMASI VARIABLE TRANSFORMATOR UNTUK MENGATUR TEGANGAN KELUARAN BERBASIS MIKROKONTROLER
}

\author{
Basten Bastory Rochim*), Abdul Syakur, dan Budi Setiyono \\ Departemen Teknik Elektro, Universitas Diponegoro \\ Jl. Prof. Sudharto, SH, Kampus UNDIP Tembalang, Semarang 50275, Indonesia \\ ${ }^{*}$ E-mail:bastorybasten@gmail.com
}

\begin{abstract}
Abstrak
Sistem otomasi di zaman sekarang berkembang dengan sangat pesat hingga hampir semua aspek pekerjaan menggunakan otomasi dalam menyelesaikan pekerjaan. Untuk itu dibuatlah perancangan kontrol tegangan variable transformator ini menggunakan otomasi menggunakan mikrokontroler STM32F103C8T6 dan aktuatornya berupa servo continuous DF15RSMG. Variable transformator ini akan digunakan sebagai masukan tegangan untuk trafo sign sehingga akan menghasilkan tegangan tinggi. Sampai saat ini variable transformator yang digunakan masih dengan menggunakan metode manual yaitu menggunakan tangan untuk memutar knopnya dan membaca tegangan aslinya menggunakan multimeter. Untuk membaca nilai tegangan AC dari keluaran variable transformator menggunakan sensor ZMPT101B menggunakan penundaan T/4 OSG (Orthogonal Signal Generator). Metode Kontrol yang digunakan adalah metode on/off dan PI(Proporsional Integral). Pada pengujian respon sistem dengan referensi tetap menggunakan kontroler PI dengan nilai Kp 1,0 dan Ki 0,05 dihasilkan Td sebesar 6 detik, Tr sebesar 14 detik, Tp sebesar 14 detik, Ts sebesar 15 detik, dan Mp yang dihasilkan adalah 0,08\%. Pengujian menggunakan kontroler ini lebih baik responnya jika dibandingan dengan pengujian menggunakan kontroler lainnya. Pada pengujian respon dengan pemberian gangguan semua kontroler yang diuji dapat merespon dengan baik.
\end{abstract}

Kata Kunci: Variable transformator, Sensor ZMPT101B, Servo DF15RSMG Mikrokontroler STM32F103C8T6, Metode kontrol PI, Metode kontrol on-off.

\begin{abstract}
Automation systems today are growing so rapidly that almost all aspects of work use automation in completing work. For this purpose a variable voltage transformer control design is made using automation using the STM32F103C8T6 microcontroller and the actuator is a continuous DF15RSMG servo. This transformer variable will be used as the input voltage for the sign transformer so that it will produce high voltage. Until now the transformer variable used is still using the manual method, which is using the hand to rotate the knob and read the original voltage using a multimeter. To read the AC voltage value from the output variable transformer using the ZMPT101B sensor. Control methods used are on / off and PI (Proportional Integral) methods. In testing the system response with a reference to using the PI controller with a value of Kp 1.0 and Ki 0.05 generated Td of 6 seconds, Tr of 14 seconds, Tp of 14 seconds, Ts of 15 seconds, and the Mp produced is $0.08 \%$. Testing using this controller is better in response when compared to testing using other controllers. In testing the response by giving interference to all the tested controllers can respond well.
\end{abstract}

Keywords: Variable transformator, Sensor ZMPT101B, Servo DF15RSMG Mikrokontroler STM32F103C8T6, PI control method, on-off control method.

\section{Pendahuluan}

Sistem otomasi di zaman sekarang berkembang dengan sangat pesat hingga hampir semua aspek pekerjaan menggunakan otomasi dalam menyelesaikan pekerjaan. Menggunakan otomasi berarti dapat mempermudah, memberikan keamanan dan kesan canggih pada pekerjaan dengan begitu maka pekerja dapat melakukan pekerjaannya tanpa harus mempersulit dirinya sendiri. Salah satu pekerjaan yang dapat dilakukan dengan otomasi tersebut adalah mengatur nilai setpoint dan monitor terhadap nilai tegangan AC pada penelitian ini. Variable transformator merupakan sebuah trafo yang dapat diatur tegangan keluarannya dengan rentang $0-250 \mathrm{~V}$ AC. Variable transformator ini akan digunakan sebagai masukan tegangan untuk trafo sign sehingga akan menghasilkan tegangan tinggi. Sampai saat ini variable transformator yang digunakan masih dengan menggunakan metode manual yaitu menggunakan tangan untuk memutar knopnya dan membaca tegangan aslinya menggunakan multimeter. Untuk itu dibuatlah perancangan kontrol tegangan variable transformator ini 
menggunakan otomasi menggunakan mikrokontroler STM32F103C8T6 dan aktuatornya berupa servo continuous DF15RSMG. STM32F103C8T6 dipilih karena spesifikasi melebihi mikrokontroler lain dengan frekuensi kerjahingga $72 \mathrm{MHz}$, flash memory $64 \mathrm{~KB}$ dan ADC 12 bit[1]. Servo continuous dipilih karena variable transformator memerlukan sudut putar lebih dari 270 derajat. Modul sensor tegangan ZMPT101B adalah sensor tegangan yang terbuat dari transformator tegangan ZMPT101B. Sensor ini mudah untuk digunakan dan dilengkapi dengan multi turn trim potensiometer untuk menyesuaikan output ADC. Untuk dapat menemukan hasil yang lebih antara tegangan input dan output ADC menggunakan analisis regresi. Output ADC disesuaikan dengan trimpot ke nilai yang sesuai terhadap masukan referensi[2]. PLL (Phase locked loop) bisa digunakan untuk memonitor besaran tegangan jaringan. Dalam penundaan T / 4 delay OSG berdasarkan PLL, kuadratur input sinyal cukup dihasilkan dengan menunda sinyal input dengan jumlah $1 / 4$ periode. Saat ini berbagai sinyal berubah ke bentuk dc dengan rata-rata transformasi park dimana fase informasi yang diumpankan ke blok transformasi park diturunkan dari output sistem umpan balik PLL [3]. Perancangan kontrol menggunakan metode PI dan on-off sebagai pembandingnya dengan feedback dari sensor ZMPT101B berupa tegangan AC. Dalam aplikasinya di lapangan, Kontrol Proporsional Integral biasanya digunakan untuk pengontrolan proses yang memiliki dinamika relative cepat. Berdasarkan sebuah survey dinyatakan bahwa hampir $80 \%$ kontroler PID yang terinstal di industri menggunakan kontrol PI dalam operasinya[4]. Filter eksponensial adalah filter yang sederhana namun cukup kuat untuk memberikan hasil yang baik. Filter eksponensial memiliki parameter yaitu nilai $\alpha$. Nilai $\alpha$ dapat dipilih dalam rentang 0 hingga 1 . Jika nilai $\alpha$ semakin besar besar hasil pemfilteran kurang halus, tetapi respons filter adalah lebih cepat. Semakin kecil $\alpha$ memberikan hasil penyaringan yang halus, tetapi respons filter lebih lambat. Filter eksponensial adalah dipilih karena hasil yang halus diinginkan. Dengan menggunakan filter eksponensial dengan 9.995 x 10-4 untuk nilai $\alpha$ dan metode perhitungan fix point, waktu eksekusi lebih efisien dan lebih cepat[5]. Tujuan dari penelitian ini adalah merancang dan mengimplementasikan sistem otomasi variable transformator sebagai masukan tegangan untuk trafo sign sehingga mendapatkan hasil pembacaan yang akurat, presisi dan sesuai dengan setpoint yang diinginkan.

\section{Metode}

\subsection{Perancangan Perangkat Keras}

Perancangan perangkat geras dari otomatisasi variable transformator berbasis mikrokontroler meliputi perancangan komponen elektronik dan mekanik penggerak servo. Spesifikasi perancangan otomatisasi variable transformator berbasis mikrokontroler ini terdiri dari:
1. Variable transformator sebagai plant utama untuk memberikan variasi tegangan input ke sistem.

2. Servo DF15RSMG sebagai aktuator untuk menggerakkan knop variable transformator untuk mendapatkan tegangan AC yang sesuai dengan setpoint.

3. Catu daya sebagai sumber daya bagi semua komponen yang digunakan.

4. Mikrokontroler STM32F103C8T6 digunakan sebagai unit kontroler untuk mengaplikasikan kendali close loop, Kontrol PI, mengirim data setpoint dan data sensor ke laptop untuk dimonitor.

5. Sensor ZMPT101B adalah sensor tegangan AC sebagai pembaca nilai tegangan dan umpan balik untuk sistem.

6. Modul bluetooth HC-05[6] sebagai modul yang digunakan untuk melakukan komunikasi serial ke laptop.

7. Laptop sebagai penampil tanggapan sistem (proses monitoring)

\subsubsection{Perancangan Komponen Elektronik}

Pada gambar 1 menjelaskan mengenai perancangan komponen elektronik pada penelitian ini, modul XL4015 sebesar 5-7V akan memberikan supply ke mikrokontroler dan motor servo agar dapat bekerja. Supply pada ZMPT101B diberikan oleh mikrokontroler sebesar 3,3V dan ZMPT101B mengirimkan data analog ke mikrokontroler. Mikrokontoler akan mengolah data tersebut dengan kontroler PI untuk mengirimkan sinyal kontrol kepada servo untuk mendapatkan setpoint yang diinginkan. Servo akan menggerakkan knop variable transformator untuk mengubah nilai tegangan dan akan berhenti ketika samapia setpoint. Data berupa nilai tegangan actual dari variable tranformator akan ditampilkan pada laptop menggunakan komunikasi serial dengan modul bluetooth HC 05. Mikrokontroler yang digunakan adalah STM32F103C8T6 dari ST® Electronics dengan basis ARM® Cortex-M3 dalam platform BluePill. STM32F103C8T6 adalah mikrokontroler 32-bit Reduce Instruction Set Computing (RISC) buatan STMicroelectronics yang memiliki arsitektur dan berbasis prosesor ARM® Cortex-M3 [1].

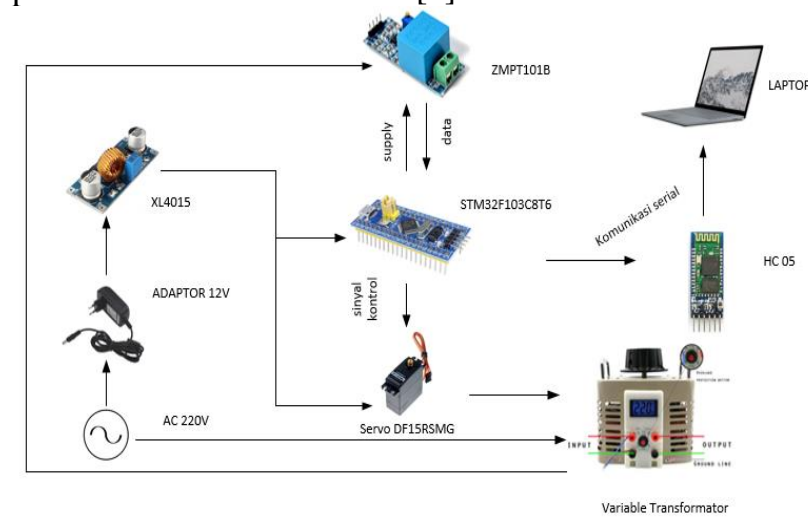

Gambar 1. Perancangan Komponen Elektronik 
a. Perancangan Mikrokontroler STM32F103C8T6

Pada Tabel 1 menjelaskan mengenai konfigurasi input dan output yang dipakai pada penelitian ini. Pin PA0 digunakan untuk menerima data analog dari ZMPT101B sebagai pembacaan data tegangan $\mathrm{AC}$ dari keluaran variable transformator. Pin PA1 digunakan untuk memberikan sinyal PWM untuk mengatur kecepatan servo. Kontrolnya menggunakan kontrol PI karena memiliki kontrol yang baik dan mudah digunakan untuk servo. Pin PA9 dan PA10 digunakan sebagai komunikasi serial ke laptop sehingga grafik setpoint dan tegangan $\mathrm{AC}$ dapat dilihat di layar monitor . Dengan begini mikrokontroler memiliki fungsi sebagai pembacaan data sensor, pengendalian servo dan komunikasi data.

Tabel 1. Penempatan pin-pin IO pada papan mikrokontroler

\begin{tabular}{|c|c|c|c|}
\hline 1/0 & Sinyal & Jenis & $\begin{array}{c}\text { Pin pada } \\
\text { mikrokontroler }\end{array}$ \\
\hline Input & $\begin{array}{c}\text { Sensor } \\
\text { ZMPT101B }\end{array}$ & Analog & PAO \\
\hline Output & $\begin{array}{l}\text { Sinyal PWM } \\
\text { Servo }\end{array}$ & Analog & PA1 \\
\hline Output & $\begin{array}{l}\text { Modul Bluetooth } \\
\text { HC-05 }\end{array}$ & Serial UART & PA9 (Tx), PA10 (Rx) \\
\hline
\end{tabular}

\section{b. Perancangan Sensor ZMPT101B}

Modul sensor tegangan ZMPT101B adalah sensor tegangan yang terbuat dari transformator tegangan ZMPT101B. Sensor ini memiliki akurasi tinggi, konsistensi yang baik untuk voltase dan tenaga pengukuran dan bisa mengukur sampai $250 \mathrm{~V}$ AC. Sensor ini mudah untuk digunakan dan dilengkapi dengan multi turn trim potensiometer untuk menyesuaikan output ADC. Untuk dapat menemukan hasil yang lebih antara tegangan input dan output ADC menggunakan analisis regresi. Output ADC disesuaikan dengan trimpot ke nilai yang sesuai terhadap masukan referensi[2].

Perhitungan untuk menghasilkan nilai tegangan dari hasil pembacaan tegangan AC dapat menggunakan rumus :

$$
\begin{aligned}
& V_{\text {peak }}=\sqrt{2} V_{R M S} \\
& V_{R M S}=\frac{V_{\text {peak }}}{\sqrt{2}}
\end{aligned}
$$

Data yang masuk ke mikrokontroler akan diolah menjadi data penampil tegangan rms AC keluaran variable transformator. Gambar 2 menunjukkan konfigurasi pin sensor ZMPT101B.

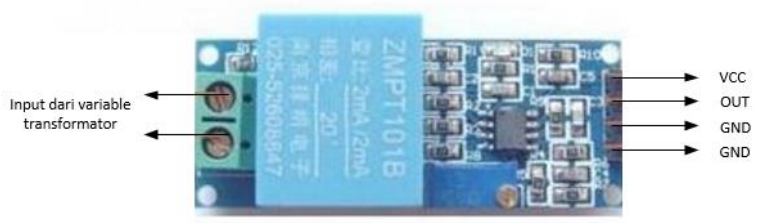

Gambar 2. Konfigurasi pin sensor ZMPT101B

c. Perancangan Servo DF15RSMG

Servo DF15RSMG memerlukan supply 5-7.4V dari buck converter. Kabel sinyal dihubungkan ke pin A1 pada mikrokontoler untuk mengirimkan sinyal pwm sebagai pengatur putaran servo. Gambar 3. menunjukkan konfigurasi pin servo DF15RSMG[7].

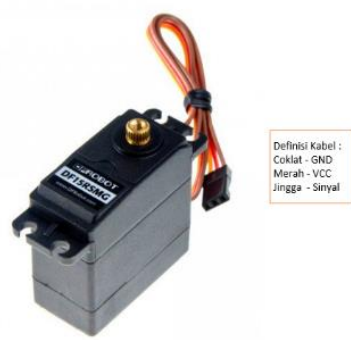

Gambar 3. Konfigurasi pin servo DF15RSMG

\section{d. Variable Transformator}

Variable Transformator yang digunakan pada penelitian ini menggunakan spesifikasi sebagai berikut[8] :

$\begin{array}{ll}\text { Type } & : \text { TDGC2-2 } \\ \text { Capacity } & : 2 \mathrm{KVA} \\ \text { Output Current } & : 8 \mathrm{~A} \\ \text { Output Voltage } & : 0-250 \mathrm{~V} \\ \text { Input Voltage } & : 220 \mathrm{~V} \\ \text { Voltage Setting } & : \text { Manual Control }\end{array}$

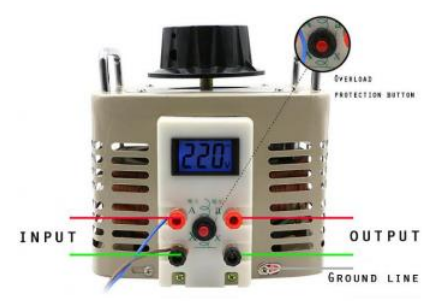

Gambar 4. Variable transformator

\subsubsection{Mekanik Pemutar Variable Transformator}

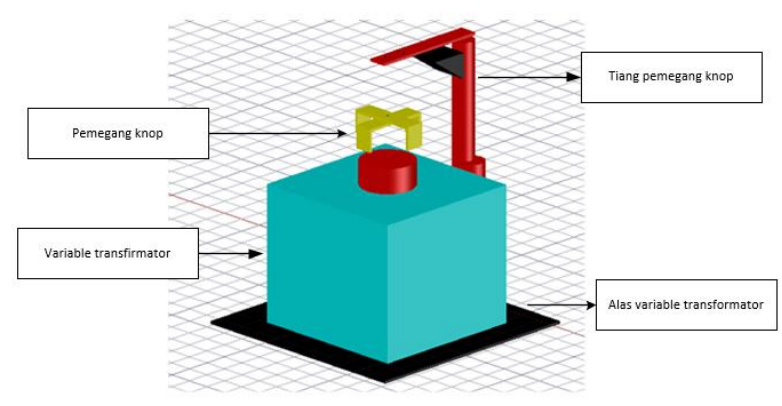

Gambar 5. Desain pemutar variable tranformator

Mekanik pemutar variable transformator digunakan sebagai penopang variable transformator supaya dapat bekerja sesuai dengan yang diingikan. Terdiri dari tiang pemegang knop, pemegang knop dan alas variable transformer berbahan besi. Tiang pemegang knop yag berdiameter $2 \mathrm{~cm}$ berfungsi sebagi penopang yang dapat 
diatur ketinggiannya sesuai dengan ketinggan dari variable transformator sehingga dapat lebih mudah untuk penggunaanya. Maksimal tinggi yang dapat ditampung dari mekanisme ini adalah $28 \mathrm{~cm}$. Pemegang knop memiliki peran yang penting untuk pemutaran variable transformer, pemegang knop dapat diatur kekuatan pencengkramannya agar servo dapat menggerakan variable transformator dengan baik. Untuk mengatur pencengkramannya dapat dilakukan dengan cara memutar baut pada sisi pemegang knop. Kemudian bagian alas hanya sebagai wadah agar tiang dapat berdiri dengan baik. Ukuran alas variabel transformator memiliki luas $22 \times 22$ $\mathrm{cm}$. Pemegang knop memiliki diameter $7 \mathrm{~cm}$. Pada Gambar 5. menunjukkan desain pemutar variable transformator.

\subsection{Algoritma dan Diagram Alir Sistem}

2.2.1. Algoritma dan Diagram Alir Pembacaan Sensor

Pada bagian ini terdiri dari algoritma dan diagram alir pembacaan sensor ditunjukkan pada Gambar 6 .

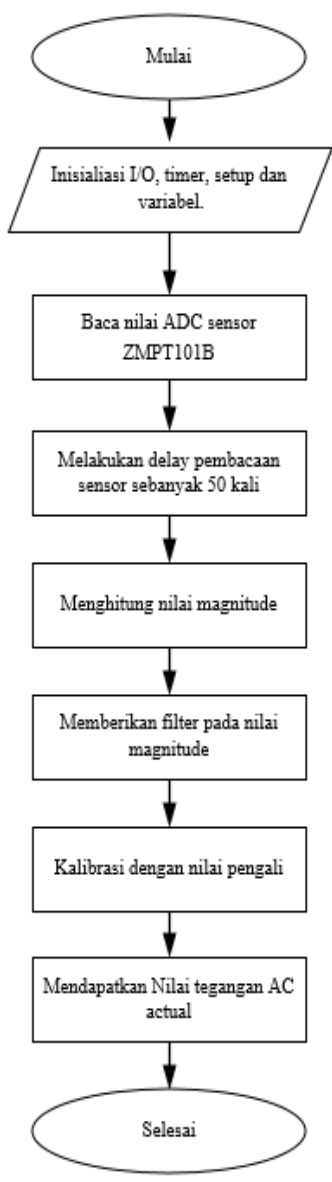

Gambar 6. Diagram alir pembacaan sensor ZMPT101B

Algoritmanya adalah sebagai berikut :

a. Mulai.

b. Inisialiasi I/O dan variabel. c. Baca nilai ADC sensor ZMPT101B.

d. Melakukan delay pembacaan sensor sebanyak 50 kali.

e. Menghitung nilai magnitude.

f. Memberikan filter pada nilai magnitude.

g. Kalibrasi dengan nilai pengali.

h. Mendapatkan Nilai tegangan AC actual

i. Selesai

\subsubsection{Algoritma dan Diagram Alir Penggerakkan Servo}

Pada bagian ini terdiri dari algoritma dan diagram alir penggerakkan servo ditunjukkan pada Gambar 7 . Algoritmanya adalah sebagai berikut :

a. Mulai.

b. Memasukkan nilai setpoint.

c. Membaca nilai tegangan actual (voltageAktual).

d. Menghitung nilai error ( $\mathrm{e}=$ setpoint - voltageAktual).

e. Penentuan penggerakkan servo jika menggunakan kontrol PI

- Jika e $>2$, maka nilai pwm $=1550<$ nilai pwm $<1570$

- Jika e $<-2$, maka nilai pwm $=1410<$ nilai pwm $<1450$

- Jika $-2<\mathrm{e}<2$, maka nilai pwm $=1500$

Untuk kontrol on-off nilai PWM nya pasti 1550 dan 1440 .

f. Selesai.

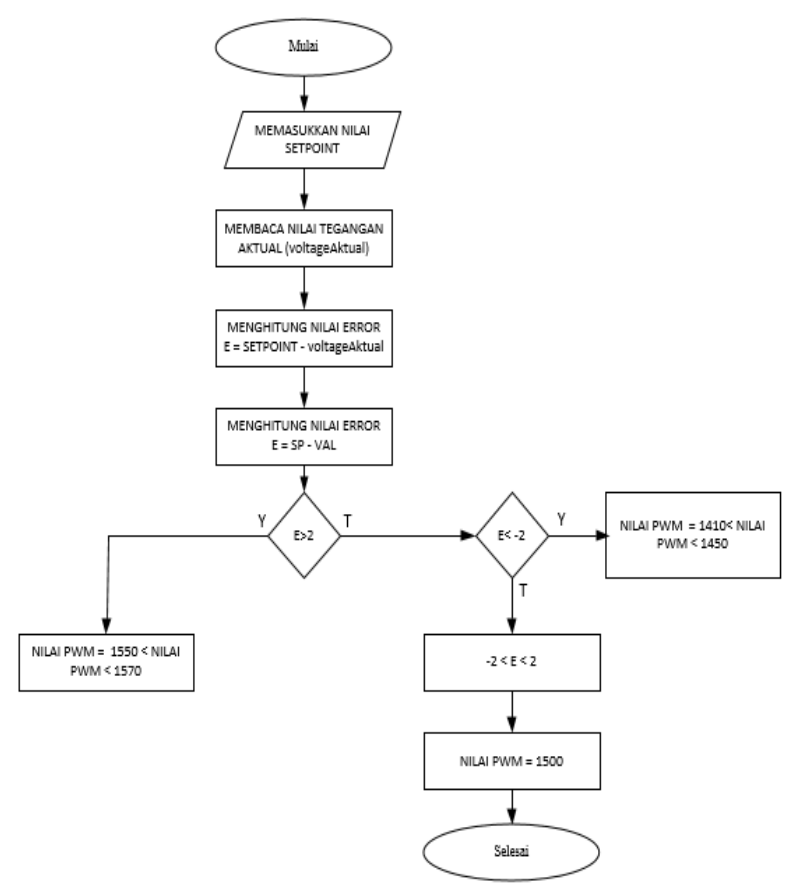

Gambar 7. Diagram alir penggerakkan servo

\subsection{Perancangan Perangkat Lunak}

2.3.1. Pemrograman Pembacaan Sensor

a. Pengukuran magnitude tegangan ac bedasarkan T/4 delay OSG (Orthogonal Signal Generator)

Persamaan (3) menunjukkan bahwa besarnya sinusoidal sinyal yang tertunda oleh $1 / 4$ periode sama dengan cosinus 
nilai dari sudut saat ini. Amplitudo atau besarnya a sinyal dapat diungkap dengan menggunakan identitas trigonometri di persamaan (4)[4].

$\sin \left(\theta-\frac{\pi}{4}\right)=\cos (\theta)$

$A(t)=\sqrt{\left(A_{m} \sin (\theta)\right)^{2}+\left(A_{m} \cos (\theta)\right)^{2}}$

$A(t)=A_{m}$

Pengambilan sampel frekuensi yang digunakan dalam kasus ini adalah $10 \mathrm{kHz}$, untuk pengambilan sampel sinyal tegangan, yang berarti gelombang sinus $50 \mathrm{~Hz}$ periodik akan diambil sampelnya 200 sampling data setiap periode. Memperoleh 1/4 penundaan periode berarti sinyal harus ditunda 50 sampel jika sinyal tersebut diasumsikan sekitar $50 \mathrm{~Hz}$ frekuensi. Komunikasi data menggunakan komunikasi serial oleh modul Bluetooth HC-05 untuk mengirimkan data pada interface.

\section{b. Eksponensial Filter}

Filter eksponensial adalah filter yang sederhana namun cukup kuat untuk memberikan hasil yang baik, Persaman (6) mewakili persamaan filter eksponensial. Filter eksponensial memiliki parameter yaitu nilai $\alpha$. Nilai $\alpha$ dapat dipilih dalam rentang 0 hingga 1 . Jika nilai $\alpha$ semakin besar besar hasil pemfilteran kurang halus, tetapi respons filter adalah lebih cepat. Semakin kecil $\alpha$ memberikan hasil penyaringan yang halus, tetapi respons filter lebih lambat. Filter eksponensial adalah dipilih karena hasil yang halus diinginkan. Dengan menggunakan filter eksponensial dengan 9.995 x 10-4 untuk nilai $\alpha$ dan metode perhitungan fix point, waktu eksekusi lebih efisien dan lebih cepat[4]. $X(t)=\alpha u(t)+(1-a) X(t-1)$

\subsubsection{Pemrograman Penggerakkan Servo}

Pemrograman penggerakkan servo berisi logika untuk memutar servo berputar searah jarum jam, berlawanan arah jarum jam dan berhenti. digunakan merupakan hasil dari perhitungan kontroler PI. Apabila error lebih dari $1.2 \mathrm{~V}$, maka servo akan berputar searah jarum jam sedangkan apabila error kurang dari $-1.2 \mathrm{~V}$ akan berputar berlawanan dengan arah jarum jam. Servo akan berhenti berputar bila error memiliki range antara $-1.2<\mathrm{e}<1.2$. Nilai pwm yang memiliki nilai 1440 akan mengendalikan servo untuk berputar berlawanan arah jarum jam. Sedangkan nilai pwm yang memiliki nilai lebih dari 1550 akan mengendalikan servo untuk berputar searah jarum jam.

\section{Hasil dan Analisis \\ 3.1. Kalibrasi Sensor Tegangan ZMPT101B}

Pengaturan trimpot dilakukan sebagai kalibrasi awal agar gelombang keluaran pengkondisi sinyal sesuai dengan kriteria input mikrokontroler STM32F103C8T6. Hasil Kalibrasi ditunjukkan pada Tabel 2. Dari Tabel 2. dapat dilihat bahwa masing-masing tegangan memiliki Vpp yang berbeda untuk keperluan pembacaan tegangan sensor
ZMPT101B. Hasil tersebut sudah sesuai dengan keperluan mikrokontroler.

Tabel 2. Kalibrasi sensor ZMPT101B

\begin{tabular}{cccc}
\hline Tegangan & $V p p$ & $V \max$ & $V \min$ \\
\hline 50 & 0,2 & 1,76 & 1,56 \\
60 & 0,24 & 1,8 & 1,56 \\
70 & 0,28 & 1,84 & 1,52 \\
80 & 0,32 & 1,84 & 1,52 \\
90 & 0,36 & 1,88 & 1,52 \\
100 & 0,4 & 1,88 & 1,48 \\
110 & 0,44 & 1,88 & 1,44 \\
120 & 0,48 & 1,92 & 1,44 \\
130 & 0,52 & 1,96 & 1,44 \\
140 & 0,56 & 1,96 & 1,4 \\
150 & 0,56 & 1,96 & 1,4 \\
160 & 0,6 & 2 & 1,4 \\
170 & 0,64 & 2 & 1,36 \\
180 & 0,68 & 2,04 & 1,36 \\
190 & 0,72 & 2,04 & 1,32 \\
200 & 0,76 & 2,08 & 1,32 \\
210 & 0,8 & 2,08 & 1,28 \\
220 & 0,8 & 2,08 & 1,28 \\
\hline
\end{tabular}

\subsection{Pengujian Pembacaan Data Sensor Tegangan ZMPT101B}

Tabel 3. Pengujian Sensor Tegangan ZMPT101B

\begin{tabular}{|c|c|c|c|c|}
\hline No & $\begin{array}{c}\text { Tegangan } \\
\text { Multimeter (V) }\end{array}$ & $\begin{array}{c}\text { Tegangan } \\
\text { Sensor } \\
\text { ZMPT101B (V) }\end{array}$ & Error (V) & $\begin{array}{c}\text { Error } \\
(\%)\end{array}$ \\
\hline 1 & 50 & 51.45 & 1.45 & 2.900 \\
\hline 2 & 55 & 56.37 & 1.37 & 2.491 \\
\hline 3 & 60 & 60.85 & 0.85 & 1.417 \\
\hline 4 & 65 & 65.77 & 0.77 & 1.185 \\
\hline 5 & 70 & 70.24 & 0.24 & 0.343 \\
\hline 6 & 75 & 75.61 & 0.61 & 0.813 \\
\hline 7 & 80 & 80.53 & 0.53 & 0.663 \\
\hline 12 & 105 & 105.14 & 0.14 & 0.133 \\
\hline 13 & 110 & 110.06 & 0.06 & 0.055 \\
\hline 14 & 115 & 115.43 & 0.43 & 0.374 \\
\hline 15 & 120 & 120.35 & 0.35 & 0.292 \\
\hline 16 & 125 & 125.27 & 0.27 & 0.216 \\
\hline 17 & 130 & 130.19 & 0.19 & 0.146 \\
\hline 18 & 135 & 135.11 & 0.11 & 0.081 \\
\hline 19 & 140 & 140.48 & 0.48 & 0.343 \\
\hline 20 & 145 & 145.4 & 0.4 & 0.276 \\
\hline 21 & 150 & 150.77 & 0.77 & 0.513 \\
\hline 22 & 155 & 155.25 & 0.25 & 0.161 \\
\hline 23 & 160 & 160.17 & 0.17 & 0.106 \\
\hline 24 & 165 & 165.54 & 0.54 & 0.327 \\
\hline 25 & 170 & 170.46 & 0.46 & 0.271 \\
\hline 26 & 175 & 175.38 & 0.38 & 0.217 \\
\hline 27 & 180 & 180.3 & 0.3 & 0.167 \\
\hline 28 & 185 & 185.22 & 0.22 & 0.119 \\
\hline 29 & 190 & 190.14 & 0.14 & 0.074 \\
\hline 30 & 195 & 195.51 & 0.51 & 0.262 \\
\hline 31 & 200 & 200.88 & 0.88 & 0.440 \\
\hline 32 & 205 & 205.36 & 0.36 & 0.176 \\
\hline 33 & 210 & 210.28 & 0.28 & 0.133 \\
\hline 34 & 215 & 215.65 & 0.65 & 0.302 \\
\hline 35 & 220 & 220.57 & 0.57 & 0.259 \\
\hline 36 & 225 & 225.04 & 0.04 & 0.018 \\
\hline 37 & 230 & 229.52 & 0.48 & 0.209 \\
\hline \multicolumn{3}{|c|}{ Error rata - rata } & 0.448 & 0.458 \\
\hline
\end{tabular}


Pengujian sensor tegangan ZMPT101B dilakukan dengan membandingkan tegangan AC yang terbaca oleh sensor melalui mikrokontroler dengan tegangan AC yang terbaca oleh multimeter digital. Hasil pengukuran dan pembacaan sensor tegangan masing-masing dapat dilihat pada Tabel 3 . Berdasarkan Tabel 4.4 Rata-rata error pembacaan tegangan sensor yaitu sebesar $0.448 \mathrm{~V}$ atau $0.458 \%$.

\subsection{Pengujian Respon Sistem Kontroler On-Off 3.3.1. Pengujian Respon Sistem dengan Referensi Tetap}

Pengujian respon sistem dengan referensi tetap dilakukan dengan mengirimkan setpoint tegangan sebesar $150 \mathrm{~V}$ melalui interface. Respon yang dihasilkan sistem dengan referensi tetap ditunjukkan pada Gambar 8. Dapat dilihat bahwa kontrol on-off mampu mencapai dan mempertahankan keluaran sesuai dengan setpoint $150 \mathrm{~V}$ dengan tanggapan respon transien untuk waktu tunda $(\mathrm{Td})$ sebesar 7 detik, waktu naik (Tr) sebesar 19 detik, waktu puncak (Tp) sebesar 19 detik, waktu penetapan (Ts) sebesar 20 detik, dan maximum overshoot (Mp) yang dihasilkan dapat diperoleh melalui perhitungan adalah 0,81 $\%(1,22 \mathrm{~V})$. Dari hasil pengujian respon sistem dengan referensi tetap dapat disimpulkan bahwa kontrol on-off mampu bekerja dengan baik dalam merespon error yang terjadi sehingga respon sistem yang dihasilkan dapat mencapai setpoint tegangan $150 \mathrm{~V}$.

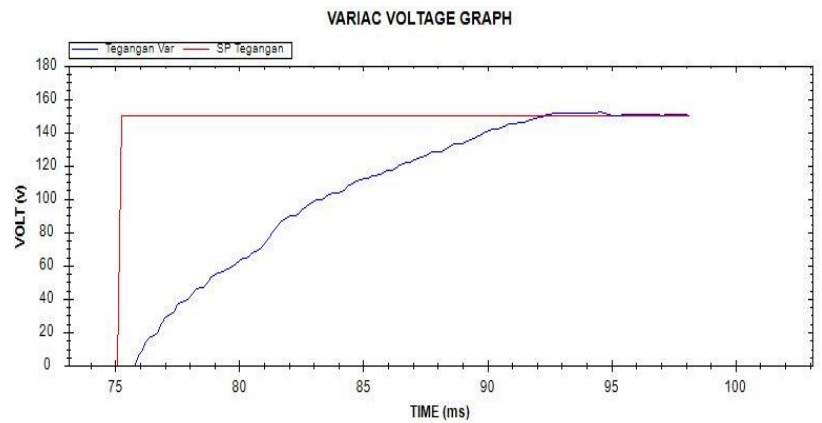

Gambar 8. Pengujian Referensi Tetap Kontroler On-Off

\subsubsection{Pengujian Respon Sistem dengan Referensi Naik}

Pengujian respon sistem dengan referensi naik dilakukan dengan mengubah setpoint tegangan dari $100 \mathrm{~V}$ naik menjadi $150 \mathrm{~V}$. Hasil pengujian respon sistem dengan referensi naik ditunjukkan pada Gambar 9. Dapat dilihat bahwa kontrol on-off mampu mencapai dan mempertahankan tegangan sesuai dengan kenaikan setpoint tegangan menjadi $150 \mathrm{~V}$ dengan tanggapan respon transien untuk Td sebesar 3 detik, Tr sebesar 7 detik, Tp sebesar 7 detik, Ts sebesar 8 detik, dan Mp yang dihasilkan adalah $0,08 \%(0,12 \mathrm{~V})$. Dari hasil pengujian respon sistem dengan referensi naik dapat disimpulkan bahwa kontroler on-off mampu bekerja dengan baik dalam mencapai kenaikan setpoint tegangan menjadi $150 \mathrm{~V}$.

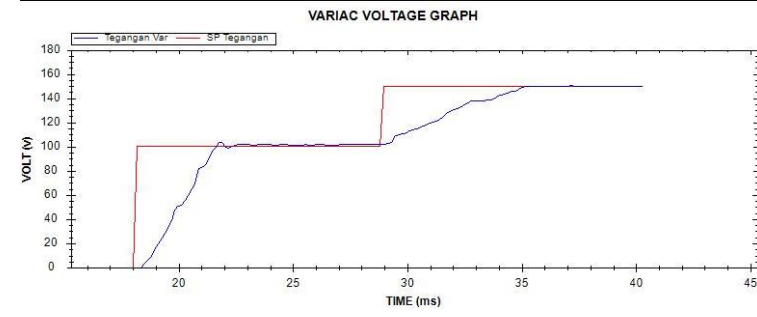

Gambar 9. Pengujian Referensi Naik Kontrol On-Off

\subsubsection{Pengujian Respon Sistem dengan Referensi Turun}

Pengujian respon sistem dengan referensi turun dilakukan dengan mengubah setpoint dari $150 \mathrm{~V}$ turun menjadi $100 \mathrm{~V}$. Pengujian ini dilakukan untuk mengetahui kemampuan kontroler on-off dalam menanggapi penurunan setpoint tegangan. Hasil pengujian respon sistem dengan referensi turun ditunjukkan pada Gambar 10. Dapat dilihat bahwa kontroler on-off mampu mencapai dan mempertahankan referensi tegangan sesuai dengan penurunan referensi menjadi $100 \mathrm{~V}$ dengan tanggapan respon transien untuk Td sebesar 3 detik, Tr sebesar 5 detik, Tp sebesar 5 detik, Ts sebesar 6 detik, dan Mp yang dihasilkan adalah 0,13\% $(0.13 \mathrm{~V})$. Dari hasil pengujian respon sistem dengan referensi turun dapat disimpulkan bahwa kontroler on-off mampu bekerja dengan baik dalam mencapai penurunan setpoint tegangan menjadi $100 \mathrm{~V}$.

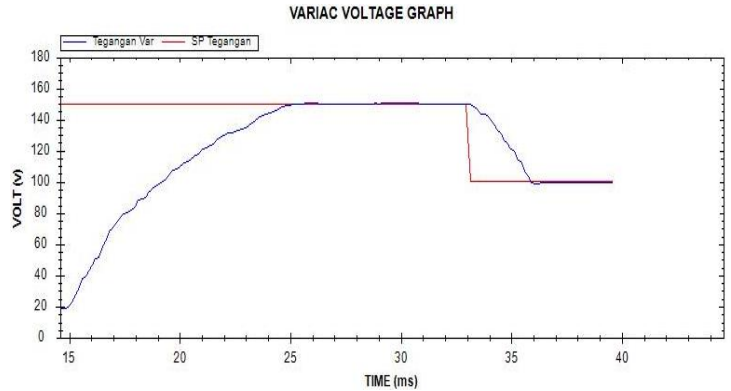

Gambar 10. Pengujian Referensi Turun Kontroler On-Off

\subsection{Pengujian Respon Sistem Kontroler PI \\ 3.4.1. Pengujian Respon Sistem dengan Referensi Tetap $(K p=1,0$ dan $K i=0,005)$}

Pengujian respon sistem dengan referensi tetap dilakukan dengan mengirimkan setpoint tegangan sebesar $150 \mathrm{~V}$ melalui interface. Respon yang dihasilkan sistem dengan referensi tetap ditunjukkan pada Gambar 11. Dapat dilihat bahwa kontrol PI mampu mencapai dan mempertahankan keluaran sesuai dengan setpoint $150 \mathrm{~V}$ dengan tanggapan respon transien untuk waktu tunda (Td) sebesar 6 detik, waktu naik (Tr) sebesar 14 detik, waktu puncak (Tp) sebesar 14 detik, waktu penetapan (Ts) sebesar 15 detik, dan maximum overshoot (Mp) yang dihasilkan dapat diperoleh melalui perhitungan adalah $0,08 \%(0,12 \mathrm{~V})$. Dari hasil pengujian respon sistem dengan referensi tetap 
dapat disimpulkan bahwa kontroler PI mampu bekerja dengan baik dalam merespon error yang terjadi sehingga respon sistem yang dihasilkan dapat mencapai setpoint tegangan $150 \mathrm{~V}$.

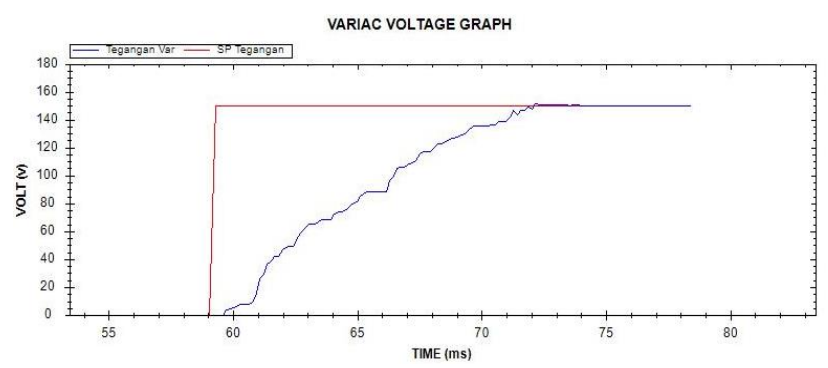

Gambar 11.Pengujian Referensi Tetap $\mathrm{Kp}=1$ dan $\mathrm{Ki}=0,005$

\subsubsection{Pengujian Respon Sistem dengan Referensi Naik $(K p=1,0$ dan $K i=0,005)$}

Pengujian respon sistem dengan referensi naik dilakukan dengan mengubah setpoint tegangan dari $100 \mathrm{~V}$ naik menjadi $150 \mathrm{~V}$. Hasil pengujian respon sistem dengan referensi naik ditunjukkan pada Gambar 12.

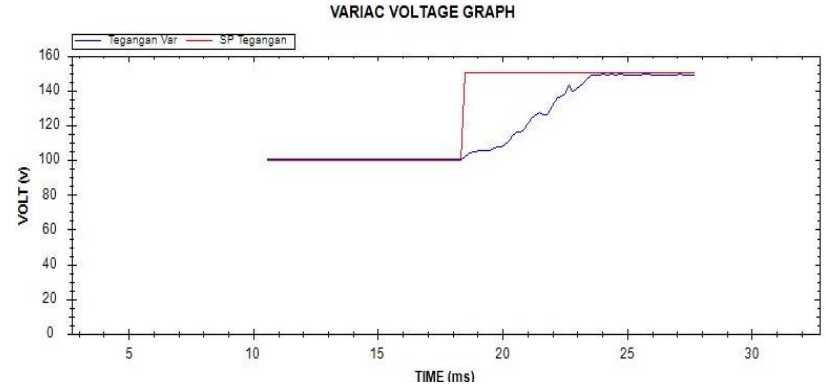

Gambar 12. Pengujian Referensi Naik $K p=1$ dan $K i=0,005$

Berdasarkan hasil respon sistem pada referensi naik pada Gambar 12 dapat dilihat bahwa kontrol PI mampu mencapai dan mempertahankan tegangan sesuai dengan kenaikan setpoint tegangan menjadi $150 \mathrm{~V}$ dengan tanggapan respon transien untuk Td sebesar 3 detik, Tr sebesar 6 detik, Tp sebesar 6 detik, Ts sebesar 7 detik, dan Mp yang dihasilkan adalah 0,68\% (1,02 V). Dari hasil pengujian respon sistem dengan referensi naik dapat disimpulkan bahwa kontroler PI mampu bekerja dengan baik dalam mencapai kenaikan setpoint tegangan menjadi $150 \mathrm{~V}$.

\subsubsection{Pengujian Respon Sistem dengan Referensi Turun $(K p=1,0$ dan $K i=0,005)$}

Pengujian respon sistem dengan referensi turun dilakukan dengan mengubah setpoint dari $150 \mathrm{~V}$ turun menjadi $100 \mathrm{~V}$. Hasil pengujian respon sistem dengan referensi turun ditunjukkan pada Gambar 13.

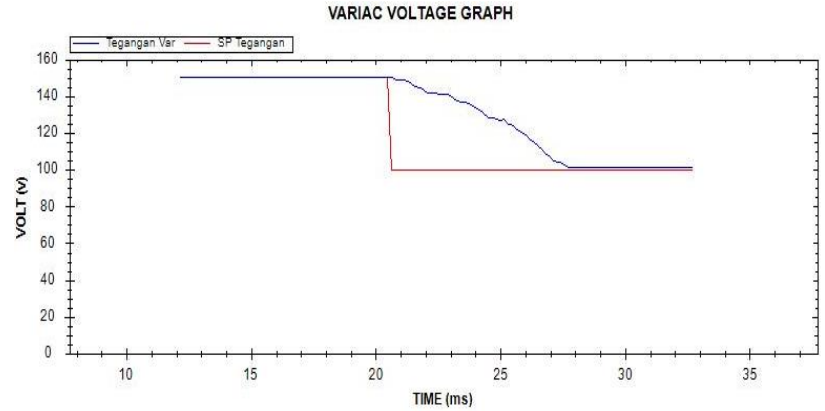

Gambar 13.Pengujian Referensi Turun $\mathrm{Kp}=1$ dan $\mathrm{Ki}=0.005$

Dapat dilihat bahwa kontroler PI mampu mencapai dan mempertahankan referensi tegangan sesuai dengan penurunan referensi menjadi $100 \mathrm{~V}$ dengan tanggapan respon transien untuk Td sebesar 5 detik, Tr sebesar 8 detik, Tp sebesar 8 detik, Ts sebesar 9 detik, dan Mp yang dihasilkan adalah $0,73 \%(1.11 \mathrm{~V})$. Dari hasil pengujian respon sistem dengan referensi turun dapat disimpulkan bahwa kontroler PI mampu bekerja dengan baik dalam mencapai penurunan setpoint tegangan menjadi $100 \mathrm{~V}$.

\section{Kesimpulan}

Berdasarkan pengujian dan analisis yang dilakukan dalam perancangan otomasi variable transformator untuk mengatur tegangan keluaran berbasis mikrokontroler, didapatkan kesimpulan bahwa hasil pengukuran dan pembacaan sensor tegangan ZMPT101B menghasilkan rata-rata error pembacaan tegangan sensor yaitu sebesar $0.448 \mathrm{~V}$ atau $0.458 \%$. Error terjadi akibat noise dari keluaran ZMPT101B dan kalibrasi tegangan kerja yang biasa digunakan dalam sistem. Pada pengujian respon sistem dengan referensi tetap menggunakan kontroler PI dengan nilai Kp 1,0 dan Ki 0,05 dihasilkan Td sebesar 6 detik, Tr sebesar 14 detik, Tp sebesar 14 detik, Ts sebesar 15 detik, dan Mp yang dihasilkan adalah 0,08\%. Pengujian menggunakan kontroler ini lebih baik responnya jika dibandingan dengan pengujian menggunakan kontroler lainnya. Pada pengujian respon sistem dengan referensi naik menggunakan kontroler PI dengan nilai Kp 1,0 dan Ki 0,05 dihasilkan Td sebesar 3 detik, Tr sebesar 6 detik, Tp sebesar 6 detik, Ts sebesar 7 detik, dan Mp yang dihasilkan adalah $0,68 \%$. Pengujian menggunakan kontroler ini lebih baik responnya jika dibandingan dengan pengujian menggunakan kontroler lainnya. Pada pengujian respon dengan pemberian gangguan semua kontroler yang diuji dapat merespon dengan baik. Perancangan dan implementasi sistem otomasi variable transformator sebagai masukan trafo sign telah mendapatkan hasil yang cukup akurat dan sesuai dengan setpoint yang diinginkan. 


\section{Referensi}

[1]. STMicroelectronics, "RM0008 STM32F101xx, STM32F102xx, STM32F103xx, STM32F105xx and STM32F107xx Rev14," Power, no. October, 2011.

[2]. I. Abubakar, S. N. Khalid, M. W. Mustafa, H. Shareef, and M. Mustapha, "Calibration of ZMPT101B voltage sensor module using polynomial regression for accurate load monitoring," ARPN J. Eng. Appl. Sci., vol. 12, no. 4, pp. 1076-1084, 2017.

[3]. I. Setiawan, T. Andromeda, M. Facta, and S. Handoko, "Implementation and Performance Analysis of a Single Phase Synchronization Technique based on T / 4 Delay PLL," vol. 8, no. 1, 2018.
[4]. I. Setiawan, Kontrol PID Untuk Proses Industri. 2008.

[5]. A. N. Luqman, "Automatic VAR / Power Factor Compensator using Fuzzy Logic based on Internet of Things," pp. 2-7.

[6]. ITead Studio, "Hc-05 Bluetooth Module," Datasheet, p. $1,2010$.

[7]. DFROBOT, "DF15RSMG 360 Degree Motor ( 20kg )," pp. 4-5.

[8]. PANDIDATIC, "Voltage Transformator," vol. 3, pp. 25 . 